ARTIGOS - ARTICLES

\title{
La historia del tiempo presente en revistas especializadas brasileñas (2007-2014)
}

\author{
Itamar Freitas de Oliveira \\ Departamento de História da UnB \\ Aluno do Programa de Pós-Graduação em História da UFRGS \\ itamarfo@gmail.com
}

Como citar este artigo: Oliveira, Itamar F. "La historia del tiempo presente en revistas especializadas brasileñas (2007-2014). Intelligere, Revista de História Intelectual, vol. 1, nº1, p. 46-57. 2015. Disponível em $<$ http://revistas.usp.br/revistaintelligere $>$. Acesso em dd/mm/aaaa.

Resumo: Este artigo apresenta um perfil de publicações periódicas especializadas em História do Tempo Presente (HTP) em circulação no Brasil entre 2007 e 2014: "Boletim do Tempo Presente", "Tempo presente", "Cadernos do Tempo Presente", Revista "Agora" e Revista "Tempo e Argumento". Em seguida, apresentamos o lugar da HTP nos textos de síntese da historiografia brasileira, o ciclo de vida dos periódicos, temas, perfis dos autores, das áreas de formação, marcos cronológicos dominantes nos artigos, filiações teóricas e institucionais. Nos resultados, destacaram-se o predomínio da bibliografia francesa como fundamento para autores brasileiros e a ausência de um consenso temporal sobre um possível tempo presente para a experiência nacional.

Palavras-chave: história do tempo presente - periódicos - historiografia brasileira experiência nacional.

\section{The history of the present time in Brazilian journals (2007-2014)}

Abstract: This article presents a profile of journals specialized in History of the Present Time (HTP) circulating in Brazil between 2007 and 2014: "Boletim do Tempo Presente", "Tempo presente", "Cadernos do Tempo Presente", Revista "Agora" e Revista "Tempo e Argumento". The aim is to shed light on the role of HTP in synthesis texts on Brazilian historiography, the journals life cycle, subjects, educational profile of authors, key chronological landmarks predominant in articles, theoretical and institutional affiliations. Results pointed to the predominance of French literature as a theoretical basis for Brazilian authors and the absence of a temporal consensus around a possible present time for national experience.

Keywords: history of the present time - journals - brazilian historiography - national experience. 
La Historia del Tiempo Presente (HTP) se concibe como un período, categoría, enfoque, campo, sub disciplina y disciplina académica, entre otras tipificaciones. Sin embargo, no es nuestra intención, en este momento, contar la historia del campo or escribir acerca de las principales cuestiones que están relacionadas con los variados significados atribuidos a la expresión. Así, no hacemos esta escoja por falta de espacio, pero porque que el mercado editorial ya ofrece las súmulas didácticas ${ }^{1}$, colecciones $^{2}$, artículos de síntesis ${ }^{3}$ y entrevistas ${ }^{4}$ disponibles en la internet.

La estrategia adoptada, sin embargo, no nos exime de informar que la HTP y sus diferencias en variadas cultura - temps présent (tiempo presente) e histoire proche (historia reciente) en Francia, contemporary history (historia contemporánea), en Inglaterra, contemporary bistory e history o four own time (historia de nuestro propio tiempo), en Estados Unidos, Zeitgeschicht (historia contemporánea), neueste Geschichte (historia más reciente) e nueste Zeitgescichte (nueva historia contemporánea), en Alemania ${ }^{5}$ - están relacionadas con experiencias individuales e institucionales, internas y externas en los dominios de los historiadores, que surgen, simultáneamente, en países, como la Alemania, Inglaterra, Francia y España. ${ }^{6}$

Esas experiencias surgen para dar respuestas a los "impresionantes cambios de las sociedades que sobrevivieron a las catástrofes del siglo XXI"7,enfatizando, ora en la experiencia relacionada a la construción/reconstrución de Estados y democracías nacionales como los estudios que abordan las causas y consecuencias de las dictaduras en Chile, Argentina, Uruguai, Paraguai e Brasil ${ }^{8}$ - ora en las cuestiones que cruzan estas mismas naciones de manera simultánea, como el terrorismo y la degradación ambiental. ${ }^{9}$ Esas cuestiones, empiezan como prácticas devotadas a lo exame de la naturaleza y consecuencias de la Segunda Guerra Mundial (1939-1945) y amplianse para la grans cuestiones experimentadas por los practicantes en sus sociedades de origen.

Fue así en Alemania, con la ascensión de lo nacionalsocialismo y el exterminio de los judíos, en España, con la Guerra Civil y el Franquismo y, en Francia, con la resistencia, el régimen colaboracionista de Vichy y las derrotas coloniales ${ }^{10}$. La HTP nace, por fin, y también,

\footnotetext{
1 Julio Aróstegui, La historia vivida: sobre la historia del preseste (Madri: Alianza, 2014); Henry Rousso, La dernière catastrophe: l'histoire, le présent, le contemporain (Paris: Gallimard, 2012).

2 Agnès Chaveau e Philippe Tétard, Questões para a bistória do presente (Baurú: Edusc, 1999); Gilson Pôrto Júnior, História do tempo presente (Bauru: Edusc, 2007); Flávia Varella et. al., Tempo presente \& usos do passado (Rio de Janeiro: Editora da FGV, 2012).

${ }^{3}$ Henry Rousso, "The last catastrophe. The writing of contemporary history", Cadernos do Tempo Presente, [v. 11], Abril (2013), http://www.getempo.org/index.php/revistas/56-n-11-marco-de-2013/artigos/1691-the-last-catastrophe-the-writing-of-contemporary-history [Consultado em 03 jan. 2014].

${ }^{4}$ François Hartog, Entrevista concedida a Henrique Estrada Rodrigues e Fernando Nicolazzi, História da bistoriografia, [n.] 10, (dez. 2012): 351-371; François Dosse, Entrevista concedida a Ana Carolina Fiuza F., Historia Agora, [n.] 7 (mar. 2007), http://www.historiagora.com/revistas-anteriores/historia-agorano7/39/118-entrevista-com-francois-dosse [Consultado em 03 jan. 2014].

${ }^{5}$ Para aprender más acerca de las diferencias del termo, consultar Julio Aróstegui, La historia vivida: sobre la bistoria del preseste (Madri: Alianza, 2014), 28-31 e Henry Rousso, "The last catastrophe".

${ }^{6}$ Henry Rousso, "The last catastrophe"; Jan Palmowski y Kristina Spohr Readman, "Speaking Truth to Power: Contemporary History in the Twenty-first Century" Journal of Contemporary History, [v.] 46, n. 3 (2011): 485-505; Walther Bernecker, "La investigación histórica del "tiempo presente" em Alemania", Cuadernos de Historia Contemporánea (Madri) n. 20 (1998): 83-98.

${ }^{7}$ Julio Aróstegui, La historia vivida: sobre la historia del presente, 27.

8 Luc Capdevila, "La sombra de las víctimas oscurece el busto de los héroes: historia del tiempo presente y construcción democrática (América Latina/Europa)", Diálogos (Maringá) [vol.] 14, n. 1 (2010): 111-119.

${ }_{9}^{9}$ Kristina Spohr Readman, "Contemporary history in Europe: from mastering national pasts to the future of writing the world", Journal of Contemporary History, [v. 46], n. 3 (2011): 506-530, http://jch.sagepub.com/content/46/3/506 [Consultado em 28 fev. 2014].

${ }_{10}$ Julio Aróstegui, La historia vivida, 25 y 37-44. Es importante consultar las diferentes declaraciones acerca de la historia del tiempo presente como algo que hace parte del dominio de los historiadores. Pero, en primer lugar debemos especificar, con el testimonio de Francisco Carlos Teixeira da Silva, que el periodo mencionado no tiene una unidad en el ámbito historiográfico. Hasta mediados de la década de 1980,
} 
dentro del dominio de los historiadores, como un síntoma de una crisis de paradigma, en relación con la objetividad histórica. ${ }^{11}$

En eses citados ejemplos de países europeos, en los cuales la historia del tiempo presente logró alto grao de legitimidad en los medios académicos y políticos, por supuesto, esconden las fracturas que hacen parte de la producción de la HTP, como la división de Alemania en 1945 y la reunificación después de 1989, las disputas entre periodistas e historiadores en Francia; entre nacionalistas y los que se discutían las cuestiones transnacionales en Inglaterra. Cuando tenemos en cuenta esas fracturas es posible notar que las causas y consecuencias de la II Guerra Mundial y de la Guerra Fría, por ejemplo, pasan por la experiencia de varios países en lo siglo XX, durando hasta lo XXI.

Por otra parte, es cómodo objetar que otros desastres ocurrirán al longo de los últimos tres siglos y, por más que lo presente ya fuera experimentado como un objeto histórico en tiempos lejanos - Tucídides (460-400 a.C.) es el autor más citados. ¿Por qué razón, entonces, solamente a partir de los años 1970, la HTP se institucionaliza como una disciplina?

Para las realidades inglesas y francesas, la institucionalización fue posible porque lo principio de la "objetividad", característica dominante de la identidad de los historiadores hasta 1914, cayó, lentamente, después de la participación de los historiadores en defesa de sus naciones, durante las guerras mundiales. ${ }^{12}$ Así, Henry Rousso alega que los investigadores del presente, "marginales durante casi cien años en Francia, empezaran a dominar la corporación de historiadores" en la segunda década del siglo XXI. ${ }^{13}$

¿Porque razón crece tanto el número de practicantes de la HTP? ¿Lo que discuten eses historiadores - que es lo presente? ¿Para qué sirve? ¿Cuáles son las utilidades que tiene la HTP en el proceso de formación de personas? ¿Cuáles presentes tratan los historiadores brasileños en la última década? Este artículo intenta responder a esas cuestiones justificado por la reciente introducción de la HTP en la enseñanza de historia e, sobre todo, por la falta de un texto de síntesis que nos ofrezcan una visión panorámica de la experiencia brasileña sobre el tema.

\section{HTP en la historia de la historiografía}

Conocer y tipificar el presente historiado en Brasil no es una tarea tan agradable cuanto la originalidad de este labor puede parecer. Lo ideal sería encontramos, en las recientes historias de la historiografías brasileñas, un capítulo específico para la historia del tiempo presente. Sin embargo, como es un fenómeno muy nuevo en Brasil, que es datado en la década

principalmente en Alemania, la experiencia reciente era una "versión suave": "Esa visión" suave "de la historia del tiempo presente se puede entender, de manera clara, como la búsqueda de una solución política y emocional para apoyar los esfuerzos de reconstrucción y la creación de un proyecto de futuro, tanto en Francia como en Alemania. Del mismo modo, se puede observar, en clave psicoanalítica como una recusa a revivir el trauma. De este modo, la HTP se constituyó, desde su origen, en un tema incómodo, en un manera de 'provocar' las heridas debían ser curadas "por falta de memoria, evitando su exposición pública y reiterada [...] La mayor parte de las veces, en las bendiciones de fractura ideológica de la Guerra Fría - nadie quería, de hecho, saber exactamente lo que pasó durante la guerra y quién hizo lo qué". Francisco Carlos Teixeira Silva, Vox, voces - (re)memorar (Rio de janeiro: Multifoco, 2012), pp. 534.

11 Georg G. Iggers, Historiography in the twentieth century: from scientific objectivity to the postmodern challenge (London: Wesleyan University Press, 1997).

12 Henry Rousso, "The last catastrophe", 6; Kristina Spohr Readman, "Contemporary history in Europe, 517.

${ }^{13}$ Henry Rousso, "The last catastrophe", 9. 
de $1990^{14}$, la historia de la historiografía, todavía, no ha incorporado como objeto de estudio. Esto lo podemos comprobar, por ejemplo, en los textos de síntesis de José Jobson Arruda e José Manuel Tengarrinha $(1999)^{15}$, Francisco Iglésias $(2000)^{16}$, en las colecciones organizadas por Marcos Cezar de Freitas (1998) ${ }^{17}$, Ciro Flamarion Cardoso e Ronaldo Vainfas (2011) ${ }^{18}$ y en lo artículo que traza un panorama de la historiografía brasileña reciente, escrito por Estevão de Rezende Martins (2011) ${ }^{19}$.

La bibliografía especializada en historia de la enseñanza de historia y en la formación del profesor de historia ${ }^{20}$ sigue la misma directriz. Cuando eso no ocurre - hablamos, en particular, de lo texto de Márcia Menendes Motta. ${ }^{21}$ Por una adversidad, la HTP es presentada como algo que es correlato a lo concepto de memoria e de manera muy restrictiva ${ }^{22}$ en lo que se refiere a los instrumentos de reproducción del campo, como lo creación de grupos de investigación, instituciones de periódicos especializados y las particularidades de la enseñanza en el nivel universitario. Por lo tanto, los que se proponen a catalogar la producción tiene mismo que buscar en las pioneras e recientes colecciones ${ }^{23}$, en cerca de 800 artículos publicados, principalmente, en los periódicos Tempo Presente [2006-2014], Ahora [2007-2014], Tempo e Argumento [2009-2014] y Cadernos do Tempo Presente [2006-2014], además de las pocas obras que historian la formación del campo, pero tienen una circulación limitada, lo que ocurre con los citados autores Cristiane Bereta (2006) ${ }^{24}$ y Francisco Carlos Teixeira da Silva (2012). ${ }^{25}$

Elegimos, en ese texto, por el análisis de la producción de los cuatro periódicos que en los anuncios, títulos, alcances y editoriales asumen la palabra de historia del tiempo presente. Así, tratamos de responder las siguientes cuestiones: ¿Que temáticas son abordadas? ¿Cuáles recortes temporales son privilegiados? Cual lo perfil de los autores que escriben para eses periódicos?.

${ }^{14}$ Cristiane Bereta, "Escrever a história do tempo presente: algumas questões e possibilidades", Tempos Históricos, ed. Marechal Cândido Rondon, [vol.] 09 (2006): 257-276; Francisco Carlos Teixeira Silva, Vox, voces - (re)memorar (Rio de janeiro: Multifoco, 2012).

15 José Jobson de Arruda e José Manuel Tengarrinha, Historiografia luso-brasileira contemporânea (Bauru: Edusc, 1999); IGLÉSIAS, Francisco. Os historiadores do Brasil: capítulos de historiografia brasileira. Rio de Janeiro: Nova Fronteira; Belo Horizonte, MG: UFMG, IPEA, 2000.

16 Francisco Iglésias, Os historiadores do Brasil: capitulos de historiografia brasileira (Rio de Janeiro: Nova Fronteira; Belo Horizonte: UFMG, IPEA, 2000).

${ }_{17}$ Marcos Cezar de Freitas, Historiografia brasileira em perspectiva (São Paulo: Contexto, 1998).

${ }^{18}$ Ciro Flamarion Santana Cardoso, Ronaldo Vainfas, Novos Domínios da História, vol. 1, (Rio de Janeiro: Elsevier, 2012).

19 Estevão de Rezende Martins, "Conhecimento histórico e historiografia brasileira contemporânea", Revista Portuguesa de História, [v.] 42, (2011): (197-210).

${ }^{20}$ Revista Latinoamericana de Historia - (UFRGS) - Dossier Formación de profesores de historia" [2013] - En Tiempo de Historia - (UNB) - Dossier "La enseñanza de la bistoria" (2013), Tiempo y Argumento - (UDESC) - dossier "La enseñanza de la historia" [2012], Historia Hoy - Revista Electrónica de bistoria y -ANPUH Educación / BRASIL todos los tres numeros dedicados a la enseñanza de historia [2012-2013], Entrever - Periódico de las licenciaturas (UFSC) - dossier "capacitación docente y enseñanza de la bistoria "[2012], Revista de Historia y Educación (UEL) - los 10 numeros [2006/2013] dedicado a la bistoria de enseñanza, La educación en periodico(UFPR) - Dossier" historia, epistemología y la educación : retos del diálogo en tiempos de incertidumbre "[2011], Periodico de bistoria (USP) - Dossier" enseñanza de la bistoria "[2011], Rutas (UDESC) - Dossier" enseñanza de la bistoria "[2010], Antiteses (UEL) dossier "Historia y enseñanza - teorías y metodologias" [2010], Fronteras (UFGD) - dossier "enseñanza de la bistoria (2009), Historia Periodico (UFG) - dossier" enseñanza de la bistoria [2009], Revista Soltala voz (UFG) - Dossier "enseñanza de la bistoria" [2009], Antiteses (UEL), Dossier "Historia y la educación - la producción de conocimiento" [2009], y encabezado de página (UFPR) - Dossier "educación histórica" [2006].

${ }^{21}$ Márcia Motta, "História, Memória e Tempo Presente”, In: Novos Dominios da História, vol. 1, (org.) Ciro Flamarion Santana Cardoso, Ronaldo Vainfas (Rio de Janeiro: Elsevier, 2012), 21-36.

22 Gerson Moura, História de uma história (São Paulo: Editora da USP, 1995).

${ }_{23}$ Marieta de M. Ferreira, Janaína Amado, Usos e abusos da História Oral (Rio de Janeiro: Fundação Getúlio Vargas, 1996); Gilson Pôrto Júnior, História do tempo presente (Bauru: Edusc, 2007); Dilton Maynard, Visões do Mundo Contemporâneo, vol. 1 (São Paulo: Livro Pronto, 2012).

${ }^{24}$ Cristiane Bereta, "Escrever a história do tempo presente: algumas questões e possibilidades".

${ }^{25}$ Francisco Carlos Teixeira Silva, Vox, voces - (re)memorar (Rio de janeiro: Multifoco, 2012). 
Antes de responder a las cuestiones, veamos algunas de las motivaciones de cada periódico, sus ciclos de vida y los grupos que se vinculan.

\section{Un instrumento de reproducción del campo}

Las revistas científicas, como sabemos, son instrumentos de reproducción de un campo y la indicación de que algún trazo especifico está siendo estudiado por un grupo de investigadores. De hecho, fue precisamente a partir de un grupo de investigación, "O Tempo" dirigido por Francisco Carlos Teixeira da Silva, de la Universidad Federal de Río de Janeiro (UFRJ) - que se originó el Boletim do Tempo Presente [2006] transformado actualmente en Revista do Tempo Presente desde 2013. El líder de ese periódico es Karl Schuster quien coordina la línea de investigación "Historia do tempo Presente" en lo "Grupo de Estudos Socioculturais da América Latina" en la Universidad de Pernambuco - UPE. De misma manera se explica la formación del Cadernos do Tempo Presente (2010)26, derivado de los trabajos desarrollados por el "Grupo de Estudios del Tiempo Presente" - GET, sobre la coordinación de Dilton Maynard, en la Universidad Federal de Sergipe (UFS), estrechamente vinculado a lo "Tempo" UFRJ.

Lo periódico Tempo e Argumento [2009] es anunciado como una publicación del Programa de Posgrado en Historia de la Universidad del Estado de Santa Catarina (PPGH/UDESC) y surge, inspirada en las asertivas de Reinhart Kosseleck, cuando defiende la asertiva del establecimiento de un "nuevo" campo de pesquisas (Editoral del Tempo e Argumento, 2009). ${ }^{27}$ Actualmente, es coordenada por Luciana Rossato y Maria Teresa Santos Cunha.

Por último, conozcamos la Revista Agora (2007). ${ }^{28}$ El subtítulo nos indica las filiación "Periódico de Historia do Tempo Presente". Ese periódico ya empieza sus trabajos intentando diferenciar la historia del tiempo presente de la historia inmediata, tiendo como referencia los franceses Serge Bernstein e Pierre Milza. En la entrevista inaugural, publicada en el periódico, se queda más clara esa cuestión, preguntando a Ciro Flamarion Cardoso sobre el presente, el inmediato e contemporáneo (Entrevista, 2007). ${ }^{29}$ Los primero ocho números del periódicos fueron coordinados por un grupo multidisciplinar: Clarissa Fernandes do Rego Barros (servicio social), Marcos Abreu Leitão de Almeida (historia) e Pedro Henrique Campelo Torres (ciencias sociales). Actualmente, la Revista Agora es coordinada por Eduardo Meiberg de Albuquerque Maranhão Filho (historia, ciencias sociales y marketing) y no explicita ninguna filiación formal a grupos o instituciones de pesquisa.

Tabla 1 - Números publicados en periódicos especializados en HTP en Brasil (2007-

2014)

\begin{tabular}{|c|c|c|c|c|c|c|c|c|c|}
\hline Títulos & 2007 & 2008 & 2009 & 2010 & 2011 & 2012 & 2013 & 2014 & Total \\
\hline Cadernos do Tempo Presente & & & & 2 & 3 & 5 & 4 & 1 & 15 \\
\hline História Agora & 3 & 3 & 1 & 1 & 3 & 1 & 2 & 1 & 15 \\
\hline Tempo e Argumento & & & 2 & 2 & 2 & 2 & 2 & 1 & 11 \\
\hline Tempo Presente & & & & & & 3 & 3 & 1 & 07 \\
\hline TOTAL & 3 & 3 & 3 & 5 & 8 & 11 & 11 & 4 & 48 \\
\hline
\end{tabular}

Elaborado por el autor a partir de revistas especializadas

${ }^{26}$ Cadernos do Tempo Presente. São Cristóvão (2010-2014). Disponível em:

www.getempo.org/index.php/revistas.

27 Tempo e Argumento. Florianópolis (2009-2014). Disponível em:

http://revistas.udesc.br/tempoeargumento.

28 Revista Agora. Rio de Janeiro (2007-2014). Disponível em: www.historiagora.com.

${ }^{29}$ Revista Agora. Rio de Janeiro (2007-2014). Disponível em: www.historiagora.com. 
La "novedad" de los periódicos también es expresada en los conceptos entre los pares. Ningún de ellos alcanzó el prestigiado concepto "A", de acuerdo con el Web Qualis, en la área de historia, algo que nos indica cuando un periódico tiene un carácter internacional. El periódico Tiempo Presente (TP) está en proceso de evaluación. Sin embargo, mismo con el antiguo título Boletin do Tempo Presente, el periódico nunca avanzó para allá del "B4" (historia, letras, lengua y educación), siendo "B3" en otras áreas (geografía, filosofía/teología e derecho). Cadernos do Tempo Presente (CTP) es clasificado como "B3" (en historia) y "B2" (en educación). El periódico con mejor evaluación "Tempo e Argumento" (TA) es "B1" (en historia, planeamiento urbano y regional/demografía e dominio interdisciplinar). La frecuencia anual de todos los periódicos, aunque con algunas irregularidades, se ha mantenido, como se expresa en la Tabla 1.

Las tablas 1 e 2 indican que no solamente los números publicados han crecido de manera progresiva, como también los perfiles de los géneros publicados vienen cambiando en los últimos siete años. Los artículos libres, que antes representaban $86 \%$ en 2007, actualmente, son $40 \%$. Los artículos en los dossiers, por el contrario, inexistentes en 2007 , representan los mismos $40 \%$ de los artículos libres en 2014. Las entrevistas han disminuido en cuantidad y las reseñas, a pesar de representaren $17 \%$ de toda la producción, tiente una frecuencia irregular en el periodo. Las publicaciones de fuentes e traducciones son prácticamente raras.

Tabla 2 - Números de textos publicados en periódicos especializados en HTP en Brasil (2007-2014)

\begin{tabular}{lrrrrrrrrr}
\hline Gênero & $\mathbf{2 0 0 7}$ & $\mathbf{2 0 0 8}$ & $\mathbf{2 0 0 9}$ & $\mathbf{2 0 1 0}$ & $\mathbf{2 0 1 1}$ & $\mathbf{2 0 1 2}$ & $\mathbf{2 0 1 3}$ & $\mathbf{2 0 1 4}$ & Total \\
\hline Artigo & 12 & 12 & 10 & 36 & 38 & 52 & 48 & 21 & 229 \\
Artigo - dossiê & & & 14 & 11 & 58 & 21 & 55 & 21 & 180 \\
Editorial & & & 2 & 2 & 5 & 3 & 5 & 4 & 21 \\
Entrevista & 2 & 2 & 4 & 2 & 14 & 2 & 3 & 1 & 30 \\
Fontes & & & 1 & 1 & & & & 1 & 3 \\
Resenha & & 4 & 6 & 20 & 18 & 26 & 21 & 4 & 99 \\
Tradução & & & 1 & 1 & 2 & & & & 4 \\
\hline Total & 14 & 18 & 38 & 73 & 135 & 104 & 132 & 52 & 566 \\
\hline
\end{tabular}

Elaborado por el autor a partir de revistas especializadas

Es de nuestro interés directo las temáticas vehiculadas en los periódicos, por eso, nos concentraremos, a continuación, en el examen de los artículos (libres y dossiers), informando los autores, temas y temporalidades dominantes y descentradas, así como los indicios acerca de los sentidos de la historia del tiempo presente defendidos en eses periódicos.

Perfiles de los autores

¿Quién escribe en los periódicos que se apoderan como de HTP? La mitad de los autores son doctores. Los demás, estudiantes de doctorado (17\%), maestros (11), estudiantes de maestría (10\%), especialistas (1\%) graduados $(7 \%)$ y estudiantes de graduación (4\%). Teniendo la titulación más recurrente, doctorado (202 en 491 autores), comprobamos también que, en orden progresiva, lo periódico TP es más selectivo $(50 \%$ de los autores tienen doctorado), el $T A$, con $71 \%$ de doctores autores, demuestra la taja media baja de de incorporación de otras titulaciones, mientras que lo $H A$ e a CTP son los que más ofrecen 
espacios para maestros, estudiantes de maestría, especialistas, graduados y estudiantes de graduación. Respectivamente, sólo 39\% y 43\% de doctores e 20\% y 10\% de graduados y estudiantes de graduación hacen parte de los cuadros de colaboradores en el periodo. Sin embargo, especialmente en lo periodo Revista Agora, existe un gran número de autores (esencialmente en los dossiers que discuten las cuestiones de género) que son los sujetos de su propia historia e, por lo tanto, no tienen sus formaciones indicadas en algunos casos (significativa es la experiencia e no el narrador de ella).

\section{Cuadro 1 -Distribución del número de autores por área de conocimiento en los periódicos HTP (1997-1914)}

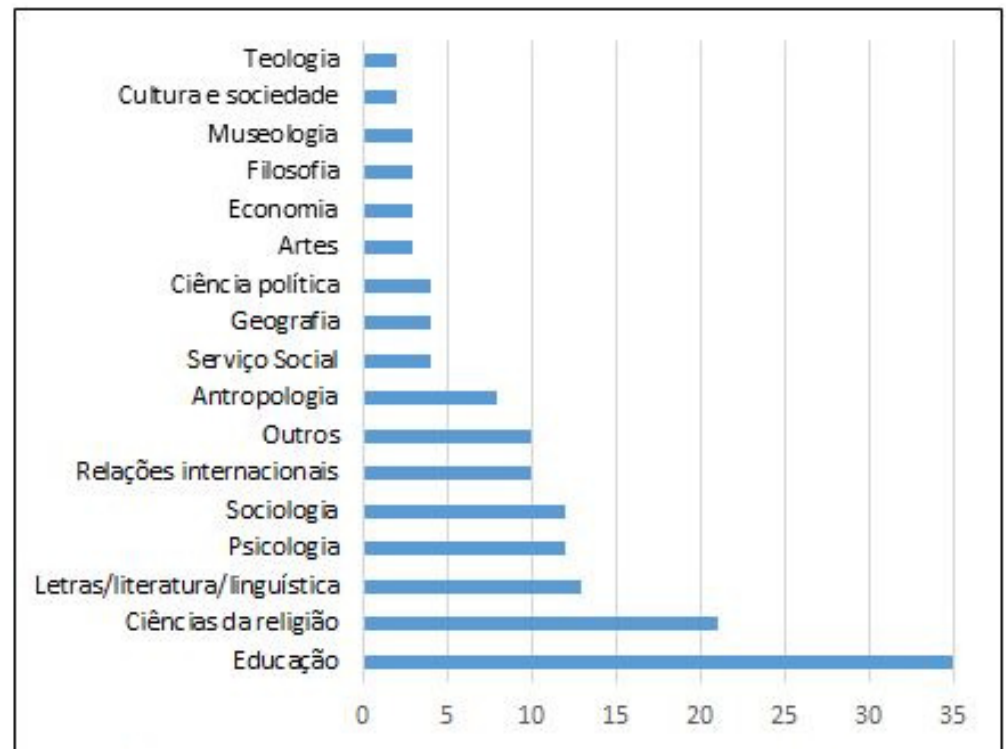

Elaborado por el autor a partir dos periódicos especializados.

Con relación a la área de actuación, las diferencias son aún mayores entre la historia e demás ciencias. Teniendo en conjunto la totalidad de los artículos, podemos decir que, en el ponto de vista del más alto grado, la interdisciplinaridad (con relación a la área de formación) no existe en los periódicos de HTP. Son 52\% profesionales de historia, es decir, 211 en 491 participantes. En lo Cuadro 1, la palabra "otros" muestra claramente la dispersión e adelgazamiento de áreas, pues constan formados en arqueología, cultura y turismo, desarrollo y medio ambiente, estructura ambiental y urbana, periodismo, actividad militar, psicoanálisis, salud y semiótica, teniendo sólo un representante en cada área.

Teniendo en cuenta las 19 especialidades citadas, también podemos identificar los periódicos que más abren espacio para la colaboración multidisciplinar. Esa es alta en $H A$, baja en CTP y en TAI es baja y muy endógena (historiadora) en TP. En este periódico, 99\% de los actores son de las áreas de historia, educación e relaciones internacionales.

\section{Las temáticas recurrentes}

Lo Cuadro 2 presenta una visión panorámica de las temáticas citadas por los colaboradores de los periódicos especializados en HTP. Tenemos en cuenta que el 
autoritarismo (en Cono Sur, Brasil de 1964-1984, en la extrema derecha nazi en Alemania, en el interior de las universidad, en Acre, en la primera mitad del siglo pasado, en la Internet en el comienzo del siglo XXI, entre otros), la biografía, enseñanza de historia, movimientos políticos (imperialismo, revolución bolivariana, petimos, chavismo, sandinistas, caras pintadas), movimientos sociales (cangaço, trangéneros, educación popular) y las relaciones internacionales y acciones de la política externa (Brasil-África, Brasil- países de la amazonia, Brasil-Mercosur, Estados Unidos- Medio Oriente, Estados Unidos - Unión Soviética, entre otros) son más recurrentes, se tenernos en cuenta la presencia en el periódico. Esas temáticas asisten a todos los periódicos, así como, la crítica científico-literaria (cine, teatro, tele, literatura) están presente en tres periódicos, los movimientos de migración (brasileños y argentinos en dirección a Italia, de mineros para los Estados Unidos, de los uruguayos a las naciones latino americanas) en dos y la historia de la Poliomielitis en uno.

Sin embargo, la presencia no indica consistencia. Nuestra investigación atesta que los periódicos $C P P, H A, T A$ son de alta diversidad temática, es decir, tienen entre 18 y 20 de los 29 temas, mientras que TP es radicalmente contrario a esa condición: movimientos políticos $(21 \%)$, estudios sobre la enseñanza de historia (18\%) e cuestiones acerca de las relaciones internacionales y/o de política externa $(12 \%)$.

Lo mismo se puede decir cuando lo cualitativo es la diferencia temática. No es el hecho del $\mathrm{R} A$ tener 22 de las 29 temáticas que lo convierten un repositorio de variados objetos, ya que 36\% de sus 166 artículos, aprobados entre 2007 y 2014 abordan la religión y religiosidad, resultando en dos enormes dossiers, publicados en 2011 y 2013.En general, podemos decir que predominan el autoritarismo (14\%), las formas de vida (11\%) y la crítica artístico literaria (11\%) en lo CTP, religión y religiosidad (33\%) y cuestiones de género (15\%) en $H A$, teoría de la historia e de la historiografía, en especial de la HTP $(20 \%)$, autoritarismo $(15 \%)$ y enseñanza de historia $(13 \%)$ en $T A$ y, como se anunció, autoritarismo $(26 \%)$, movimientos políticos $(21 \%)$ y enseñanza de historia (18\%) en TP. 
Cuadro 2 - Temáticas vehiculados en los periódicos de HTP (1997-1914)

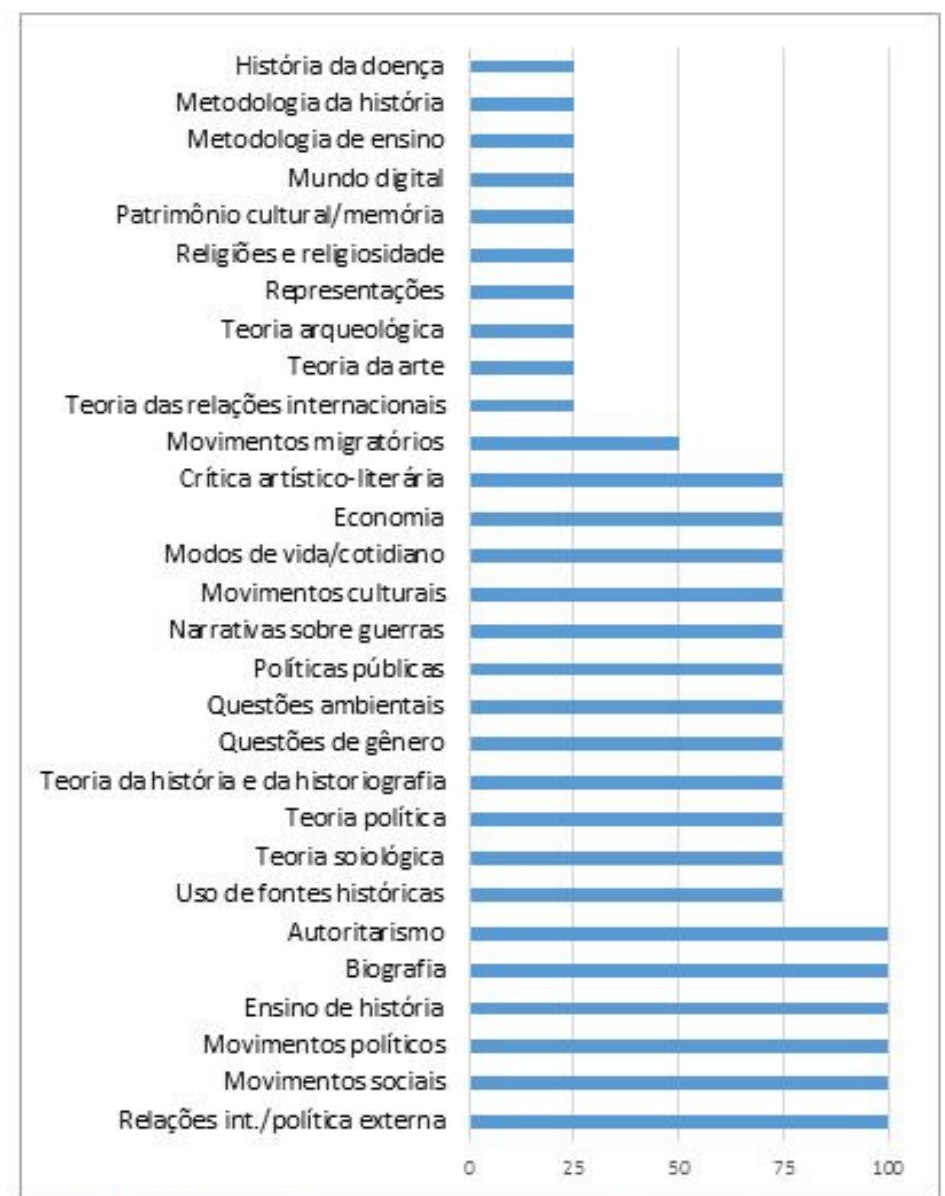

Elaborado por el autor a partir de los periódicos especializados

Dos temas, por fin, nos interesan en específico: la enseñanza, historia e teoría de la historia sobre HTP. Teoría de la historia, HTP e historia de la HTP representan 8,3\% del total de artículos publicados en los cuatro periódicos. Su naturaleza no difiere do lo que encontramos, por ejemplo, en encuestas transnacionales de periódicos en Alemania, Francia e Inglaterra. ${ }^{30}$ Los artículos de esa sección centran, en predominio, la categoría memoria e sus relaciones con lo colectivo, trauma, olvido, el acceso a los documentos públicos y a la metodología de la historia (en específico, historia oral). En una escala menor, se dan a conocer artículos que discuten los sentidos de la historia e de HTP, las ideas de verdad, acontecimiento, intersubjetividad y el pensar históricamente. Por último, hay ejercicios de historia de la historiografía académica y de la escrita de sí.

Las aportaciones teóricas que predominan (HTP, inmediato, memoria, recentismo, historicidad) son francesas, que marcan la presencia de la lengua y cultura en nuestra historiografía académica, desde la primera mitad del siglo pasado. Los más mencionados son Agnes Chauveau, François Hartog, Henry Rousso, Jaques Le Goff, Jean Lacouture, Jean Pierre Rioux, Jean-François Sirinelli, Pierre Nora, Philippe Thetard, René Rémond y Michel De Certeau. Fuera del circulo frances, aunque no tán distante, están : Michael Pollack (austríaco,

\footnotetext{
${ }^{30}$ Kristina Spohr Readman, "Contemporary history in Europe: from mastering national pasts to the future of writing the world".
} 
radicado en Francia), Pieter Lagrou (belga), Eric Hobsbawm y Peter Burke (ingleses), Nestor Maria Cancline (Mexico), Francisco Carlos Teixeira da Silva y Marieta de Morais Ferreira (brasileños).

Acerca de la enseñanza de historia, los periódicos valorizan las investigaciones sobre las estrategias de comunicación, algunos clasicos como libro texto, museos y estrategias de la educación del patrimonio y las posibilidades de uso de la Internet. Otros abordan las evaluaciones de libros texto, usos de los libros textos en escuelas religiosas, el "pensamiento histórico" de los profesores y estudiantes y las categorías "pensar históricamente", "aprender históricamente", "evento o acontecimiento" y "memoria". Observamos, pues, que se trata, en eses casos, mucho más de una historia del presente de la enseñanza de historia.

Con respecto a la HTP en la enseñanza de historia, esa ocupa 7,1\% del total de artículos y son discutidas las representaciones sobre los nativos e historia de America, el Golpe Militar de 1964, la Guerra de las Malvinas, historias de familias e actuación de Luis Carlos Prestes. También hay textos sobre el lugar de la HTP en los currículos estaduales o nacionales de Brasil, Estados Unidos, Australia, en los libros texto japoneses, argentinos y brasileños. En sus introducciones, eses textos indican la escasa producción y la posibilidad de entrada de la HTP en los currículos de Brasil por medio de la experiencia, sobre todo, europea. Los referenciales teóricos son más franceses que lo anunciado en la lista anterior y reproducen, obviamente, Rioux, Rousso e Rémond. Sin embargo, también citan las obras de Paul Ricoeur, Pierre Milza, Serge Bernstein, Maurice Agulhon, Gerárd Noiriel, Marc Bloch, del autor espaçnol Julio Aróstegui, especializados en la enseñanza como Circe Bittencourt, Kazumi Munakata, Rivair Macedo, Mário Carretero, Peter Lee, Benoit Falaize, entre otros.

\section{El tiempo cronológico que distingue del tiempo presente}

La referencia temporal no parece ser elemento importante en muchos artículos. Expresiones como "actualmente", “en el mundo contemporáneo", "en la modernidad”, en el "mundo moderno" y "hoy" son comunes, así como artículos que empiezan y cierran sin una referencia cronológica (a excepción del año de publicación de las obras citadas). Lo mismo ocurre en algunos títulos y resúmenes. ¿Qué entendemos por la frase "La testosterona cambió mi estar acá" o "Aspectos del elemento humano en la cultura de Cabo Verde"? Hay también los que anuncian la "globalización" como enfoque y reservan la mayor parte del texto para narrar la institución de la industria cultural, desde los años 20 do siglo pasado. Otro explora los fans del cantante "Ricardo Arjona" sin informar, al menos, el tiempo en que ocurre el fanatismo o la fecha de nacimiento del artista. Lo mismo ocurre con "Imágenes del Islam en la tele brasileña: el periodismo en televisión y la telenovela El Clon”.

Sin duda, gran parte de la temporalidad está relacionada a la naturaleza teórica del tema. Las idas y vueltas del tiempo, de la Grecia antigua hasta el siglo XIX, del Renacimiento a la globalización etc., a discutir los distintos sentidos de una categoría de historia, a justificar la ausencia de los límites cronológicos. Sin embargo, las muestras más flagrantes de la ausencia de límites temporales, no sabemos si por protección a los testigos o por abandono metodológico, predominan en los trabajos sobre la religión o religiosidad y las cuestiones de género. Los autores que así lo hacen, aparentan entender que su "vivido" es equivalente a el "vivido" de los lectores. Ocurre que lo artículo, mismo en formato digital, produce una historicidad, que debe ter un comienzo manifiesto por su autor.

Estas dificultades no fueran suficientes para dejarnos de establecer la clasificación que si sigue. Las Tablas 3 y 4 fueran construidas por medio del objetivo inicial indicado por los 
autores. En su mayoría, las tablas son aproximativas, debido a la frecuencia con que encontramos los termos "principio del siglo XIX", "al final del siglo XX", etc. Otros se refieren al "periodo de la dictadura militar", "globalización", "posmodernidad", etc. como una manera de limitar lo objeto de estudio. Sin embargo, es muy evidente que lo presente indicado por la mayoría de los autores (cuando no están haciendo una revisión de la literatura o a buscar "las orígenes" del fenómeno o sujeto) está situando en lo principio de la década de 90 del siglo pasado. Tres de los cuatro periódicos concentran lo numero dominante en la fisura generacional que ocurre desde 1991 hasta 2014.

Tabla 3 - Artículos publicados en periódicos especializados en HTP no Brasil Números totales (2007-2014)

\begin{tabular}{lrrrrrrr}
\hline Periódico & Total & $>1891$ & $\mathbf{1 8 9 1 - 3 0}$ & $\mathbf{1 9 3 1 - 6 0}$ & $\mathbf{1 9 6 1 - 9 0}$ & $\mathbf{1 9 9 1 <}$ & NI* \\
\hline Cadernos do Tempo Presente & 108 & 8 & 11 & 18 & 29 & 35 & 7 \\
História Agora & 161 & 18 & 9 & 16 & 43 & 46 & 29 \\
Tempo e Argumento & 122 & 0 & 18 & 39 & 33 & 20 & 12 \\
Tempo Presente & 34 & 3 & 0 & 4 & 8 & 12 & 7 \\
\hline
\end{tabular}

$\left({ }^{*}\right)$ Fueran excluidos los demás géneros: editorial, entrevistas, fuente histónica y perfil.

(**) Limites temporales no identificados

Teniendo en cuenta $50 \%$ de los artículos como un punto de corte, este periodo se expande para $2 \frac{1}{2}$ generaciones, es decir, el tiempo cronológico que incluye los años de 1931 60, 1961/90 y 1991-2014.Los números son claros: CTP- 76\%, HA-56\%, TA-75\% e TP-71\%. Pero, se seguimos mirando el último periodo, comprobaremos que el respecto a la distancia temporal, algo incuestionable en la historiografía académica del siglo XX, aparenta estar desapareciendo en este tipo de periódico.

Tabla 4 - Articulos* publicados en periódicos especializados en la HTP en Brasil Números totales (2007-2014)

\begin{tabular}{lrrrrrrr}
\hline Periódico & Total & $>1891$ & $\mathbf{1 8 9 1 - 3 0}$ & $\mathbf{1 9 3 1 - 6 0}$ & $\mathbf{1 9 6 1 - 9 0}$ & $\mathbf{1 9 9 1}<$ & $\mathbf{N I ^ { * * }}$ \\
\hline Cadernos do Tempo & & & & & & & \\
Presente & $100 \%$ & $7 \%$ & $10 \%$ & $17 \%$ & $27 \%$ & $32 \%$ & $6 \%$ \\
História Agora & $100 \%$ & $11 \%$ & $6 \%$ & $10 \%$ & $27 \%$ & $29 \%$ & $18 \%$ \\
Tempo e Argumento & $100 \%$ & $0 \%$ & $15 \%$ & $32 \%$ & $27 \%$ & $16 \%$ & $10 \%$ \\
Tempo Presente & $100 \%$ & $9 \%$ & $0 \%$ & $12 \%$ & $24 \%$ & $35 \%$ & $21 \%$ \\
\hline
\end{tabular}

(*) Fueran excluidos los demás géneros: editorial, entrevistas, fuente histónica y perfil.

(**) Limites temporales no identificados

Por supuesto, existen trabajos que exploran la duración conjetural y larga. Sin embargo, como está en la Tabla 4 (columna 1), eses artículos representan entre 7\% y 11\% del total. Además, gran parte de este total es justificado también por las mismas rasiones empleadas en la significativa porcentaje de artículos atemporales: el ídolo de las orígenes y el carácter ensayístico de algunos artículos (la falta de preocupación con el tiempo e espacio específicos en la búsqueda por el mejor argumento).

En el fin, debemos registrar que, a pesar de las menciones a las categorías claves como "trauma", "memorias que regresan" y "régimen de historicidad del presente", la mayor parte de los trabajos justifican sus marcos temporales a través de eses complejos fundamentadores, derivados de la discusión francófona, en la mayoría de las veces. Los autores parecen, simplemente, contar una historia que ocurre en el tiempo vivido y, que, por suerte (para ellos, suponemos), un periódico a constituye como historia. Es decir: se tenernos en conjunto, en total de los artículos de un periódico o en todos los artículos del general de periódicos, no percibimos tendencias o coincidencias que nos induzcan a afirmar que los 
periódicos especializados que indican o legitiman la instauración de un nuevo presente (con excepción en los años 90 del siglo pasado).

\section{Conclusiones}

Recodemos que nuestro objetivo en este articulo fué producir un perfil de los temas, autores que nos ofrecen una base que nos sirve de comparación para que, en el futuro, posamos mejor evaluar la presencia de la HTP en los currículos brasileños. Lo que creemos ser importante, en principio, es que la HTP revelada en los periódicos especializados no es una práctica de periodistas. Nos parece que el mundo académico embarga la actuación de los periodistas en tales vehículos de discusión, o que nos parece más aceptable, pues los periodistas ya narran la experiencia del presente en sus periódicos diarios o semanales, en la prensa, tele o en el formato digital.

Otro dado importante es lo ahuecamiento de la producción cuando nos acercamos del periodo más reciente, las décadas de 1990 a 2000. Es probable que la muralla de la objetividad de la ciencia, basada en una supuesta separación del pasado/presente o historia/política no tenga mucha fuerza entre los académicos que escriben en los referidos periódicos. En ese caso, lo periodismo brasileño se diferencia del periodismo alemán, inglés, francés y de norte América. ${ }^{31}$

Sobre los objetos, destacamos la dispersión y, en consecuencia, el reduzido interes en la clasica historia politica. Cuestiones de género (lesbianas, gays, mujeres), religiosidad (pentecostalismo, comunidades carismaticas, umbanda), migraciones (de mineros, uruguayos, pescadores españoles), trafico de personas (mujeres, travestis), el patrimonio cultural (artefactos, celebraciones, carnaval del Zé Pereira), mundo digital, las políticas públicas de inclusión social en la intolerancia cotidiana, las cuestiones ambientales, las narrativas de guerras (local y regional), teoría y enseñanza de la HTP parece obscurecer, por ejemplo, la reciente experiencia autoritaria del Estado.

Algo que no provoca asombro es el uso frecuente de los aportes de la HTP con matriz (o origen) francesa, a pesar de los recientes diálogos de los grupos de pesquisa brasileños con autores alemanes, ingleses y de norte américa. Esta característica marca la discusión epistemológica sobre la HTP, pero también las investigaciones diagnosticas o prescritas del uso de la HTP en la educación básica. Por supuesto, no son suficientes para indicar los periodos o la demarcación de un presente, el brasileño, que puede trasladarse al universo escolar.

${ }^{31}$ Ibid.. 